Article

\title{
Resistance to Chemical Attack of Hybrid Fly Ash-Based Alkali-Activated Concretes
}

\author{
William G. Valencia-Saavedra ${ }^{(D)}$ and Ruby Mejía de Gutiérrez *(D) \\ Composites Materials Group (CENM), Universidad de Valle, Calle, Cali 13 \#100-00, Colombia; \\ william.gustavo.valencia@correounivalle.edu.co \\ * Correspondence: ruby.mejia@correounivalle.edu.co
}

Academic Editor: Angel Palomo

Received: 13 July 2020; Accepted: 23 July 2020; Published: 27 July 2020

\begin{abstract}
The environmental impacts related to Portland cement production in terms of energy consumption, the massive use of natural resources and $\mathrm{CO}_{2}$ emissions have led to the search for alternative cementitious materials. Among these materials, alkali-activated cements based on fly ash (FA) have been considered for concrete production with greater sustainability. In the present article, the chemical durability properties (resistance to sulphates, chloride permeability, and resistance to carbonation) of a hybrid alkali-activated concrete based on fly ash-ordinary Portland cement (FA/OPC) with proportions of $80 \% / 20 \%$ were evaluated. It is noted that the FA was a low-quality pozzolan with a high unburned carbon content $(20.67 \%)$. The results indicated that FA/OPC concrete had good durability with respect to the OPC concrete, with 95\% less expansion in the presence of sodium sulphate and a $2 \%$ strength loss at 1100 days, compared with the $56 \%$ strength loss of the OPC concrete. In addition, FA/OPC showed lower chloride permeability. On the contrary, the FA/OPC was more susceptible to carbonation. However, the residual compressive strength was $23 \mathrm{MPa}$ at 360 days of $\mathrm{CO}_{2}$ exposure. Based on the results, $\mathrm{FA} / \mathrm{OPC}$, using this type of $\mathrm{FA}$, can be used as a replacement for $\mathrm{OPC}$ in the presence of these aggressive agents in the service environment.
\end{abstract}

Keywords: fly ash; hybrid concrete; alkali-activated cements; durability; sulphates; carbonation; chlorides

\section{Introduction}

The durability of concrete structures exposed to different aggressive agents is a subject of great importance for safe and efficient construction with concrete [1]. The main factors that reduce concrete durability are chemical attacks, such as carbonation, chloride attack, and sulphate attack, phenomena that can lead to the corrosion of structural steel [2]. The rate and mechanism of the different attacks depend on factors such as the type of cement, design and curing of the concrete mixture, the permeability of the material, the concentration of the attacking medium, exposure temperature, and the nature of the products formed [1,3]. Different studies have demonstrated that the durability problems in Portland cement concretes are associated with the decalcification of $\mathrm{C}-\mathrm{S}-\mathrm{H}$ and the formation of new products $[4,5]$. The addition of Supplementary Materials to Portland cement systems, such as pozzolans and blast furnace slags, reduces the proportion of portlandite present in the mixture. These materials contribute to the refining of the pore structure, resulting in lower concrete permeability and consequently higher resistance to attack from certain aggressive agents [6,7]. The crystallization of salts in very fine pores can also cause stress phenomena and cracks, negatively impacting the mechanical properties of the structure [5]; in addition, the reduction of portlandite can accelerate carbonation phenomena.

Alkali-activated concretes are a new class of cementitious materials obtained from the alkaline activation of materials with high silica and alumina contents that can contain calcium, such as fly ash (FA), metakaoline (MK), and granulated blast furnace slag (GBFS) [8-11]. These materials 
have shown excellent mechanical properties, even at early ages. However, due to the variability in the type and sources of the precursors, some of which come from industrial by-products and/or wastes, it is necessary to study the durability of these materials in different environments in depth. Studies regarding the durability of these materials are scarce, and most of the relevant studies have been performed on pastes and mortars, many at variable concentrations and for relatively short exposure periods $[12,13]$.

Škvára, Jílek, and Kopeckỳ [14] investigated the sulphate resistance of pastes and mortars up to an age of 720 days and reported the resistance increments throughout the tests, which indicated no dimensional changes nor the formation of expansion phases. These researchers presumed that sodium sulphate acted as an activator in the mixture. Puertas et al. [15], studied the behavior of slag mortars and FA/GBFS 50/50 mixtures activated with sodium silicate and sodium hydroxide, and in both cases, the activated mortars were highly resistant to sulphate attacks; however, the samples activated with $\mathrm{NaOH}$ were more susceptible to degradation due to the presence of expansive phases such as gypsum and ettringite. Ismail et al. [16], studied FA/GBFS 50/50 activated pastes exposed to sodium and magnesium sulphate at $5 \%$ for a period of three months and reported that magnesium sulphate was more aggressive due to the higher decalcification of the calcium silicate hydrate gel and the formation of gypsum, which coincides with results that have been reported for Portland cement concretes [5]. In general, FA-based systems with GBFS additions activated with a mixture of sodium hydroxide and silicate, have showed good resistance to sulphate attack (sodium and magnesium).

In contrast, the susceptibility to carbonation has been identified as a potential disadvantage of alkali-activated cements compared with Portland cement, given that in different studies, significant structural changes occur in these materials in the presence of $\mathrm{CO}_{2}$, which could compromise the long-term performance of these materials [17-20]. Most of the studies have been performed under accelerated conditions using a chemically controlled mechanism, demonstrating that the effects depend on factors such as the specific microstructural characteristics, types of precursors and nature of the activator [21]. The test conditions, such as the relative humidity and $\mathrm{CO}_{2}$ concentration, also significantly impact the rate and degree of carbonation in these materials [17]. Despite the elevated susceptibility to carbonation shown by different alkali-activated systems under laboratory conditions, no correlation was observed with the results obtained by exposing these materials to atmospheric conditions (normal, $0.035 \% \mathrm{CO}_{2}$, or reduced levels of $\mathrm{CO}_{2}$ ) over many years [22]. Thus, using the accelerated test method for evaluating the carbonation of alkali-activated materials can underestimate the real performance of these materials during their service life.

Studies regarding the performance of these materials in the presence of chlorides are scarce, and most of the studies have been performed on pastes and mortars. Rajamane et al. [23], studied the chloride ion permeability of alkali-activated systems based on GBFS and mixes GBFS+FA (25 and 50\% FA) under ASTM standard C1202, and determined that these systems had low chloride ion permeability (722 to 1222 coulombs). Ganesan et al. [24], using the same technique, evaluated FA-based alkali-activated concrete $(100 \% \mathrm{FA})$ exposed to chlorides and also reported low chloride ion permeability (1321 coulombs). Additionally, the authors using ASTM C1556 reported a chloride diffusion coefficient of $1.24 \cdot 10^{-11} \mathrm{~m}^{2} / \mathrm{s}$ [24]. In contrast, a study by Olivia and Nikraz [25] reported that the chloride permeability of alkali-activated FA concrete is higher than that of ordinary Portland cement (OPC) concrete. Shayan et al. [26] characterized the properties of a GBFS-based alkali-activated system after being in service for five years in the retaining walls of a bridge structure over the Yarra River in Melbourne, Australia. The rapid chloride permeability test ASTM C1202 showed a very low chloride permeability. Ma et al. [27] and Tennakoon et al. [28] have obtained a chloride diffusion coefficient of alkali-activated systems lower than that of OPC concrete.

In recent years, other types of alkali-activated concretes containing percentages of up to $30 \%$ OPC have been considered, which are produced with a highly blended cement after being alkali-activated. These materials have been named "Alkali-activated Portland Blended cements, or Hybrid cements" [29]. The mechanical strength development of this type of hybrid material has been studied [30], however, 
to date no durability studies have been reported. Considering that these hybrid cements with a low Portland cement content and high proportion of aluminosilicates represent a more viable option in the immediate future, it is important to investigate their performance in aggressive environments.

Based on the above, the objective of this paper was to evaluate the behavior of an alkali-activated Portland fly ash concrete (FA/OPC; 80\%/20\%) under exposure to sulphates $\left(\mathrm{Na}_{2} \mathrm{SO}_{4}\right.$ and $\left.\mathrm{MgSO}_{4}\right), \mathrm{CO}_{2}$ (in an accelerated chamber under controlled conditions), and chlorides. The results are compared with those of a concrete produced with conventional cement (100\% OPC) exposed to the same aggressive environments. It is noted that, most of the FA generated in Colombia, particularly that from industrial boilers, has showed a high carbon content due to a regular control of the combustion process, which limits its use. Therefore, this type of FA is considered a waste material and causes the contamination of the soil and atmosphere. The use of this material as a precursor of hybrid binders will allow to produce lower carbon footprint materials and increase the added value to the residue. The knowledge of its mechanical properties and durability will make its use in the civil construction sector more feasible.

\section{Results and Analysis}

\subsection{Exposure to Sulphates}

\subsubsection{Expansion Tests and Visual Inspection}

The changes in the length of the concrete bars (FA/OPC and OPC) after exposure to $\mathrm{Na}_{2} \mathrm{SO}_{4}$ and $\mathrm{MgSO}_{4}$, evaluated in accordance with the ASTM standard C1012 are included in Figure 1. The OPC samples were more affected than the FA/OPC samples in the $\mathrm{Na}_{2} \mathrm{SO}_{4}$ exposure medium, and the FA/OPC samples exposed to $\mathrm{MgSO}_{4}$ expanded more than the samples immersed in $\mathrm{Na}_{2} \mathrm{SO}_{4}$ at 450 days of exposure. At 28 days of exposure to the $\mathrm{Na}_{2} \mathrm{SO}_{4}$ solution, the OPC sample expanded by $0.050 \%$, remaining approximately stable up to 120 days, unlike the FA/OPC samples, which expanded by only $0.011 \%$ at the same age, a value that is approximately five times lower than that of the OPC sample. From this age of exposure, the expansion of the OPC samples significantly increased, reaching an expansion six times higher than that of the FA/OPC $(0.090 \%)$ at 360 days. At the final age of the test $(1100 \mathrm{~d})$, the expansion of the OPC samples again significantly increased $(2.390 \%)$, while the expansion of the FA/OPC samples only slightly increased to $0.140 \%$, which in general terms is $95 \%$ lower than that of the OPC concrete.

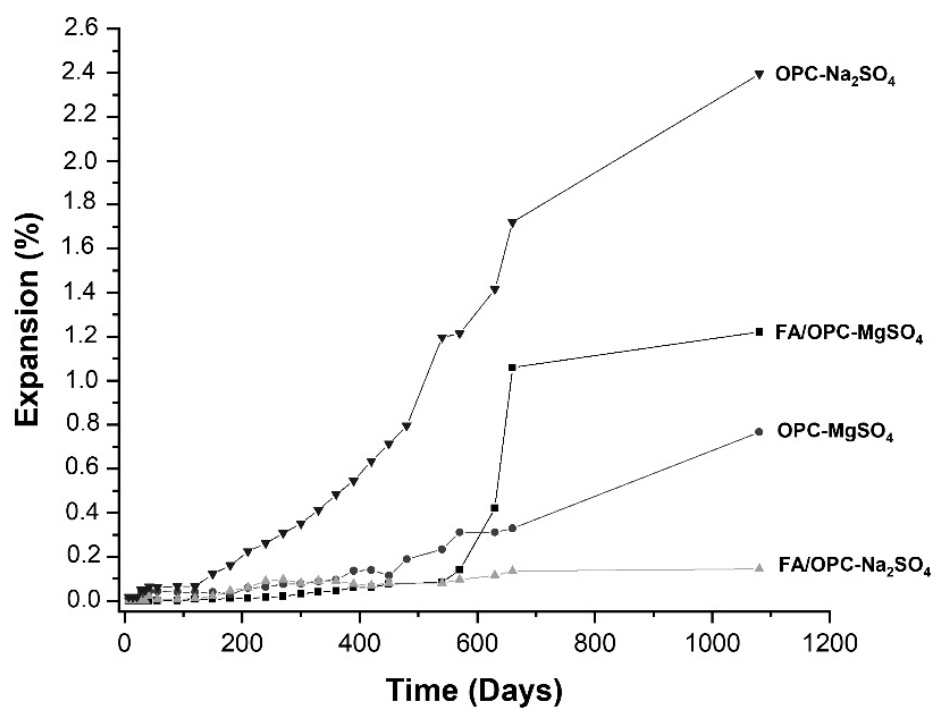

Figure 1. Expansion vs. time for the concrete exposed to $\mathrm{Na}_{2} \mathrm{SO}_{4}$ and $\mathrm{MgSO}_{4}$. 
The FA/OPC samples immersed in the $\mathrm{MgSO}_{4}$ solution did not change size during the first 120 days of exposure, unlike the conventional OPC concretes, which expanded by $0.018 \%$. At six months of exposure, the OPC concretes had expanded three times more than the FA/OPC concrete. From 630 days of exposure, the hybrid FA/OPC alkali-activated concretes expanded more than the OPC concrete, up to $30 \%$. At the end of the test $(1100 \mathrm{~d})$, the expansion of the FA/OPC concretes was 1.60 times higher than that of the $\mathrm{OPC}$ in $\mathrm{MgSO}_{4}$.

The OPC-based concretes deteriorated more than the alkali-activated FA/OPC concretes from exposure to sodium sulphate. This is due to the reaction of the sulphate with calcium hydroxide and calcium monosulfoaluminates to form gypsum and ettringite, which generate the expansion, cracking, and detachment of the surface layers in the concretes, and a finally loss of strength [31,32]. Sata et al. [33], attributed the better performance of alkali-activated mortars to the lower susceptibility to sodium sulphate of the geopolymerization products, compared with the hydration products of the Portland cement. Bakharev [34] attributes this effect to the cross-linked polymer structure of aluminosilicate gel. Regarding the samples immersed in $\mathrm{MgSO}_{4}$, the alkali-activated concretes expanded more, which also coincides with the results of Bakharev [34] and Ismail et al. [16], who attributed this behavior to the decalcification of the $\mathrm{C}-\mathrm{A}-\mathrm{S}-\mathrm{H}$ gel, forming gypsum.

Figure 2 presents photographs of the concretes immersed in $\mathrm{Na}_{2} \mathrm{SO}_{4}$ and $\mathrm{MgSO}_{4}$ at exposure ages of 210, 440, and 1100 days; more damage was observed in the OPC specimens than the FA/OPC samples, and higher degrees of damage were seen in the samples exposed to the $\mathrm{MgSO}_{4}$ solution.
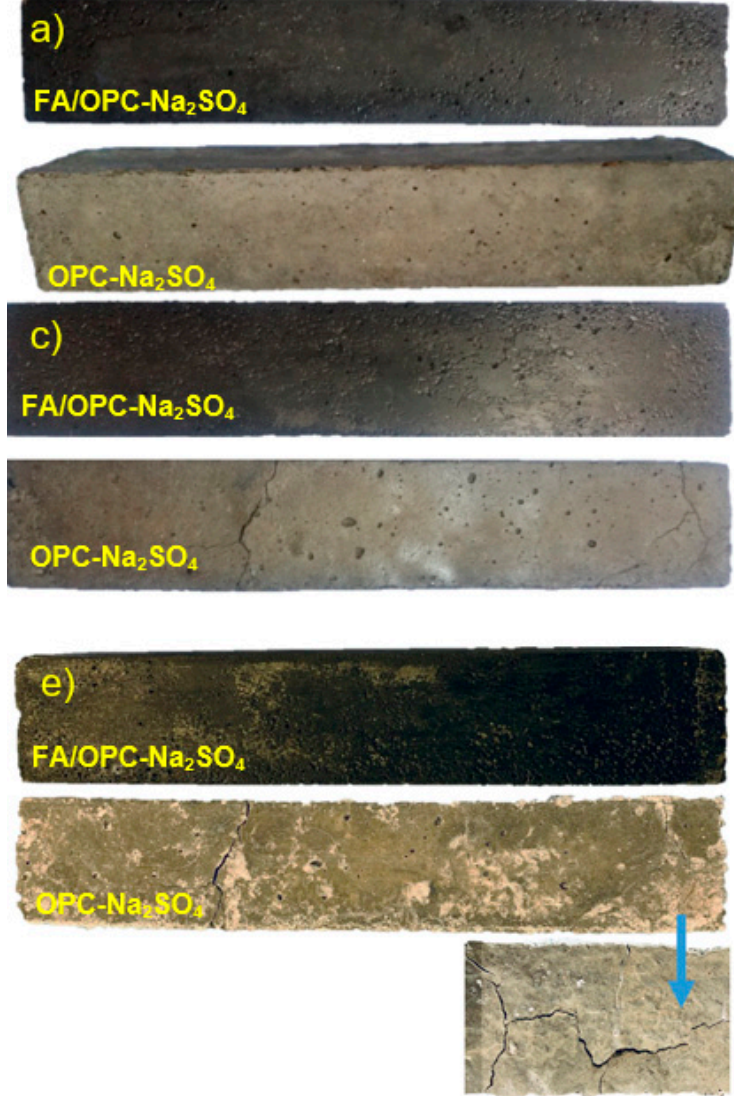
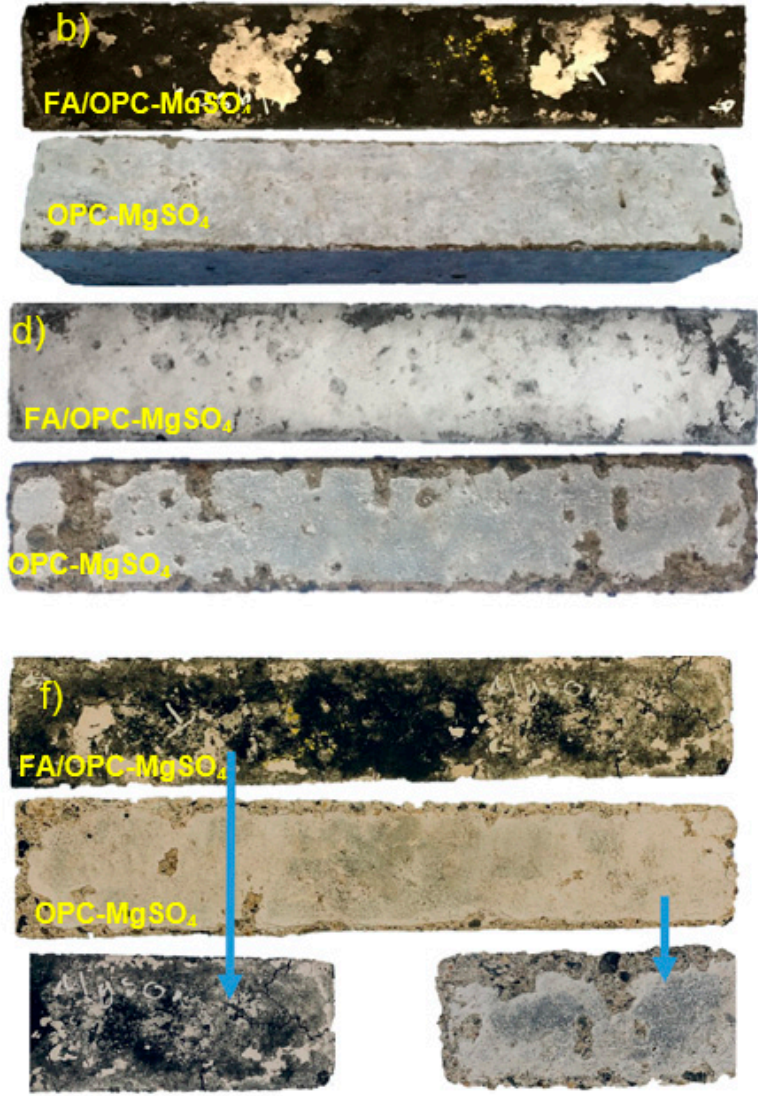

Figure 2. Concrete exposed: (a) $\mathrm{Na}_{2} \mathrm{SO}_{4}$ for 210 days; (b) $\mathrm{MgSO}_{4}$ for 210 days; (c) $\mathrm{Na}_{2} \mathrm{SO}_{4}$ for 440 days; (d) $\mathrm{MgSO}_{4}$ for 440 days; (e) $\mathrm{Na}_{2} \mathrm{SO}_{4}$ for 1100 days; and f. $\mathrm{MgSO}_{4}$ for 1100 days.

From an age of 210 days, the crumbling of the edges of the bars and attack on the surfaces were evident for the OPC specimens in the sodium sulphate solution, as shown in Figure 2a. Conversely, the FA/OPC specimens did not physically deteriorate, and only the formation of salts was observed on the surfaces with no effects on the integrity of the samples. At 440 days, as shown in Figure 2c, 
the edges of the OPC bars exhibited cracks, unlike the FA/OPC samples, whose surfaces did not change. In the magnesium sulphate solution, at the same age of exposure, the physical deterioration of the OPC bars significantly increased, and delamination was observed at the edges, as shown in Figure 2d. Furthermore, for the FA/OPC specimens, larger amounts of salt were deposited on the surface, and small surface cracks were observed (Figure $2 b, d$ ). These differences in behavior as a function of the type of sulphate solution used have been observed by other researchers in the pastes of FA/GBFS 50:50 binary mixtures [35] and fly ash-based geopolymer mortars [34].

Figure 2e shows the FA/OPC and OPC samples at 1100 days of exposure to sodium sulphate; the FA/OPC did not show signs of damage on the surface nor cracks, in contrast with the OPC concrete samples. This coincided with the low expansion values of the FA/OPC samples at this age of exposure $(0.14 \%)$ compared with the $2.40 \%$ expansion of the OPC samples. Regarding the samples immersed in magnesium sulphate, the FA/OPC concretes deteriorated more than the OPC samples; these samples presented more cracks on the surface and crumbling of the edges (Figure 2f). This behavior was due to the formation of crystalline phases of gypsum, as observed by X-ray diffraction testing. The maximum expansion limit specified by ASTM C1012 and ACI C201 for Class 3 exposure (equivalent at severe exposition, $\geq 10.0000 \mathrm{ppm} \mathrm{SO}_{4}{ }^{2-}$ ) at 18 months was $0.10 \%$; $\mathrm{FA} / \mathrm{OPC}$ complies to this value under $\mathrm{Na}_{2} \mathrm{SO}_{4}(0.080 \%)$ and $\mathrm{MgSO}_{4}(0.084 \%)$ exposure. This performance allows its classification, according the standards mentioned above, as sulphates-resistant concrete.

\subsubsection{Effect on Compressive Strength}

Figure 3a, shows the development of the compressive strength of the concrete after exposure to the magnesium sulphate and sodium sulphate $\left(\mathrm{MgSO}_{4}\right.$ and $\left.\mathrm{Na}_{2} \mathrm{SO}_{4}\right)$ solutions at ages of exposure up to 1100 days. The results obtained for the samples (FA/OPC and OPC) that were not exposed to sulphates (control samples) were also included in the same Figure. The results of each test correspond to a minimum of three specimens per age, and the deviations of the results range between 0.4 and $6 \%$. In general terms, between 60 and 120 days of exposure to sodium and magnesium sulphates, the FA/OPC concretes increased in mechanical strength compared with the control samples by orders ranging between 2 and $12 \%$. These results agree with those reported in the expansion tests, where relatively low values were observed at an age of 120 days (a maximum of $0.060 \%$ for the OPC samples and $0.005 \%$ for the FA/OPC samples). In Portland cement concretes, the initial increase in strength is supposedly due to the formation of new phases that act by filling the pores and densifying the material; however, since these phases expand, once the strength exceeds the tensile strength of the concrete, cracking occurs, and the strength drastically decreases [4].
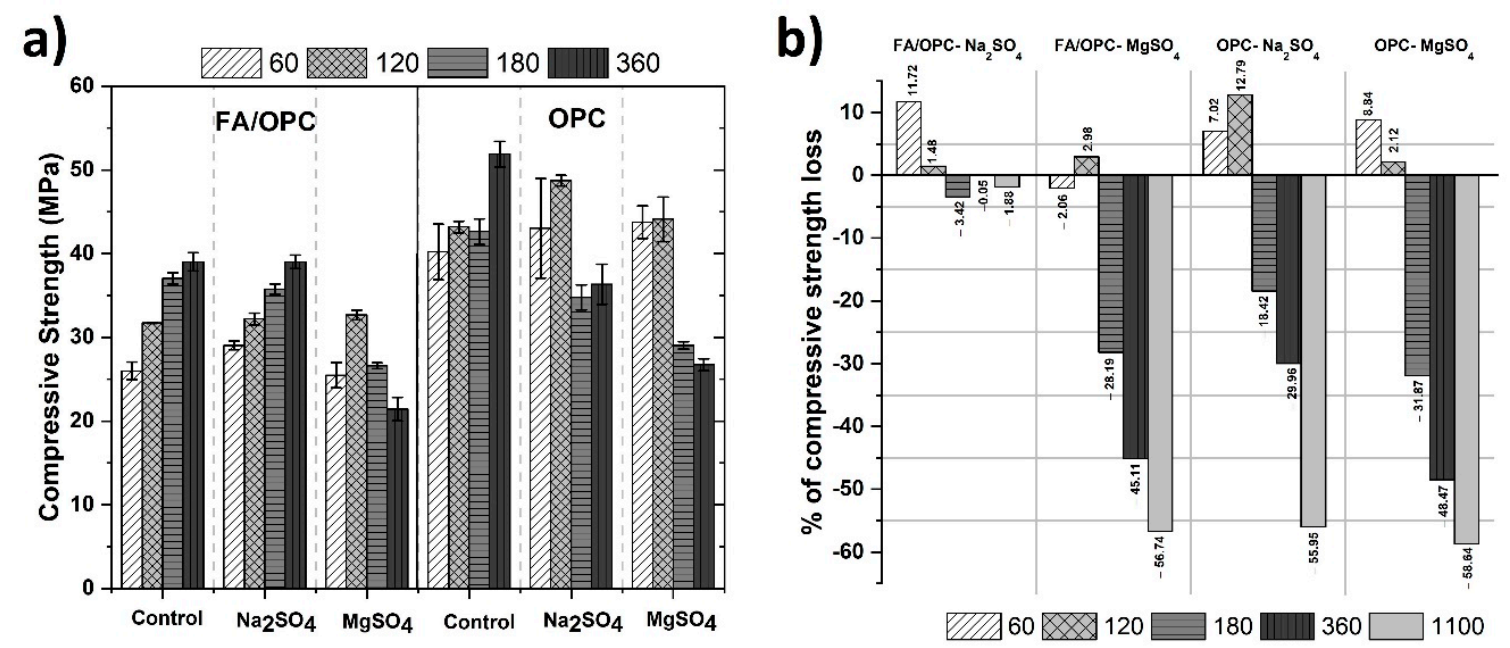

Figure 3. (a) Compressive strength and (b) loss of compressive strength of the concretes exposed to $\mathrm{MgSO}_{4}$ and $\mathrm{Na}_{2} \mathrm{SO}_{4}$. 
For the alkali-activated materials, Baščarević et al., [3] claimed that sodium sulphate can act as an activator in the material, and consequently, the mechanical strength can initially increase and decrease over the long term, although by relatively low orders; the authors reported values of $12 \%$ at 360 days under exposure to sodium sulphate. In the current study, at the age of 180 days of exposure, under exposure to $\mathrm{Na}_{2} \mathrm{SO}_{4}$ and $\mathrm{MgSO}_{4}$, the mechanical strengths of the FA/OPC and OPC concretes decreased, as shown in Figure 3b; this reduction was higher in the presence of magnesium sulphate, and higher for the OPC samples. The compressive strength loss of the FA/OPC was 3.42 and $28.19 \%$ when exposed to $\mathrm{Na}_{2} \mathrm{SO}_{4}$ and $\mathrm{MgSO}_{4}$, respectively. This behavior in the alkali-activated systems coincides with that reported in other studies and can be considered of minimal significance [16]. Regarding the OPC concrete, this behavior could be related to the formation of crystalline phases that cause expansion such as ettringite, which causes the cracking of the structure and an increase in the porosity [36]. At 360 days of exposure, the strength of the OPC in $\mathrm{Na}_{2} \mathrm{SO}_{4}$ was reduced by $30 \%$; conversely, the strength of the FA/OPC samples did not significantly vary compared with the reference samples. In $\mathrm{MgSO}_{4}$, the strength of the FA/OPC concrete decreased by $45 \%$, and that for the OPC concrete decreased by $48 \%$. At the final test ages $(1100 \mathrm{~d})$, the strength of the FA/OPC samples exposed to sodium sulphate decreased by only $2 \%$, unlike the OPC samples, which presented losses of $56 \%$. For the samples immersed in magnesium sulphate, the strength decreased up to $58 \%$; however, the behavior of the two types of concretes was similar. The mechanical performance of the concretes exposed to sulphates coincides to a high degree with what was observed in the expansion tests.

\subsubsection{Mineralogical Characterization of the Specimens by XRD and SEM}

Figure 4 presents the X-ray spectra of the FA/OPC and OPC pastes after exposure to $\mathrm{Na}_{2} \mathrm{SO}_{4}$ and $\mathrm{MgSO}_{4}$ for a period of 180 days. The spectra of the FA/OPC-Control and OPC-Control are included for comparison purposes, which correspond to the reference pastes.
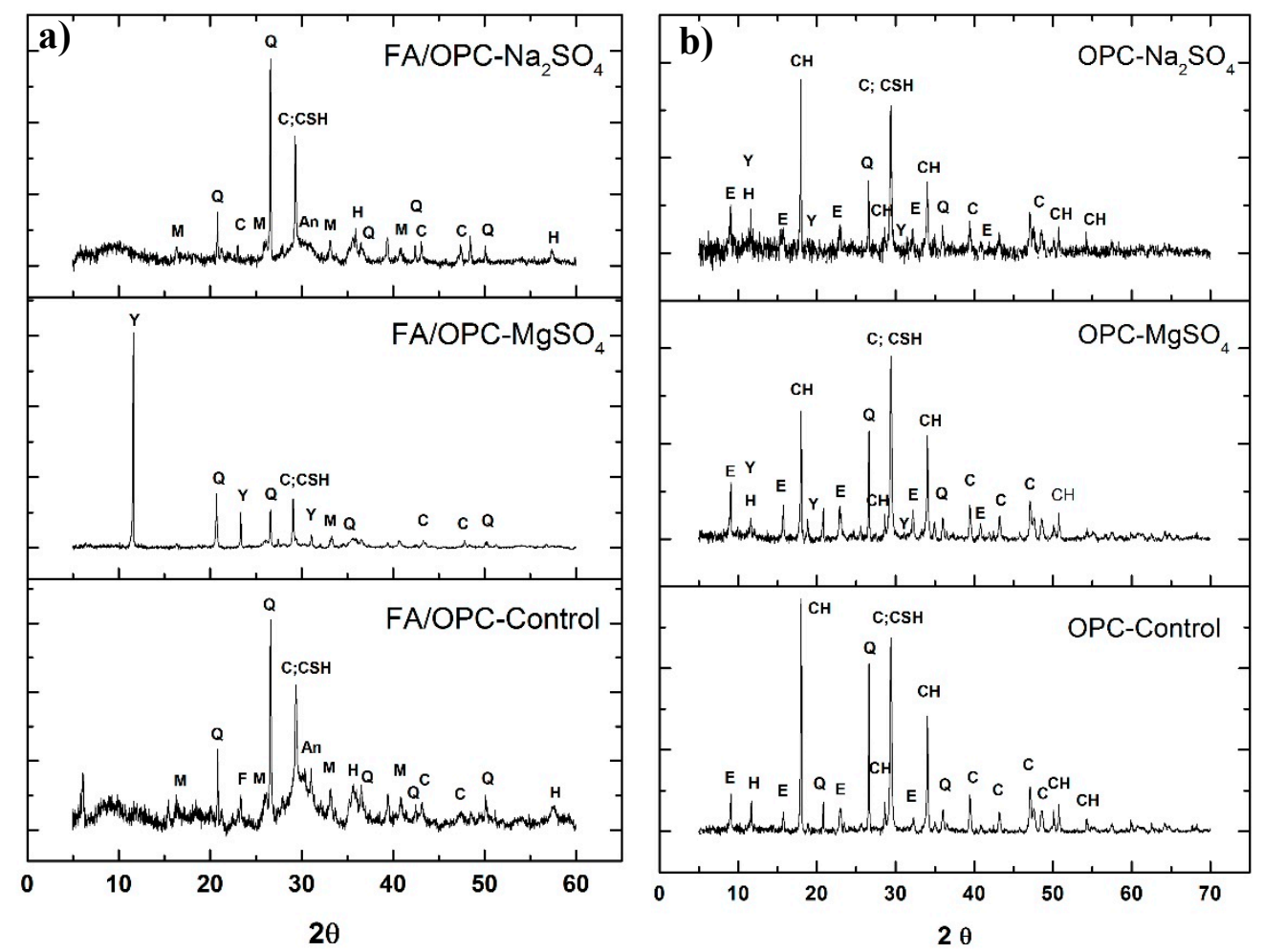

Figure 4. X-ray diffractograms for the pastes after 180 days of exposure. (a) FA/OPC and (b) OPC.

Crystalline phases that correspond to the raw materials, such as C: calcite, Q: quartz, M: mullite, and $\mathrm{H}$ : hematite, are observed in the FA/OPC-Control spectrum, in addition to the C-(A)-S-H main 
phase, which is located at approximately $30^{\circ} 2 \theta$, overlapping the calcite peak [37]. The FA/OPC samples immersed in $\mathrm{MgSO}_{4}$ present a new high-intensity phase (Y: gypsum) that can arise from the decalcification or decomposition of the $\mathrm{C}-(\mathrm{A})-\mathrm{S}-\mathrm{H}$ phase, which is corroborated by the lower intensity of the peak corresponding to the $\mathrm{C}-(\mathrm{A})-\mathrm{S}-\mathrm{H}$ phase $[2,16,38]$. The high intensity of the gypsum peak at $11.63^{\circ} 2 \theta$ may suppress the visibility of other lower-intensity peaks of the different phases present. In the FA/OPC pastes exposed to $\mathrm{Na}_{2} \mathrm{SO}_{4}$, no new crystalline phases appear compared with the FA/OPC-Control, which agrees with the results obtained in the previous tests of expansion percentage and loss of mechanical properties. This result coincides with those reported by other researchers $[3,16]$.

In the OPC-Control samples, hydration products are observed, $\mathrm{CH}$ : portlandite and E: ettringite, as well as the crystalline phases present in the original material (OPC) due to the addition of limestone (Q: quartz, C: calcite and H: hydrocalcite). The peak at $29.4^{\circ} 2 \theta$ corresponds to the calcite present in the cement and overlaps with the peak attributed to low-crystallinity calcium silicate hydrate (CSH) [39]. Ettringite and gypsum peaks are present for the samples exposed to both media, with more intense peaks for the samples immersed in the $\mathrm{MgSO}_{4}$ solution. This result coincides with the decrease in the intensities of the peaks attributed to calcite, the $\mathrm{CSH}$ phase, and $\mathrm{CH}$, which is also observed for the FA/OPC exposed to $\mathrm{MgSO}_{4}$ and is an indication of $\mathrm{CSH}$ decalcification. For the OPC concretes exposed to sodium sulphate, the formation of gypsum is reportedly associated with the formation of sodium hydroxide, which maintains a highly alkaline $\mathrm{pH}$, contributing to the higher stability of the CSH. Conversely, in the presence of magnesium sulphate, magnesium hydroxide (brucite) is formed, which is an insoluble and poorly alkaline phase, so the stability of the CSH decreases, which is the main reason why $\mathrm{MgSO}_{4}$ is more aggressive. Alexander et al. [4], and Sata et al. [33], claimed that at a $\mathrm{pH}$ of 12-12.5, only ettringite forms, whereas at a $\mathrm{pH}$ between 8 and 11.5, gypsum forms, and decalcification is preferred.

Figure 5 presents SEM micrographs of the FA/OPC and OPC pastes exposed to the $\mathrm{MgSO}_{4}$ and $\mathrm{Na}_{2} \mathrm{SO}_{4}$ solutions for 180 days.
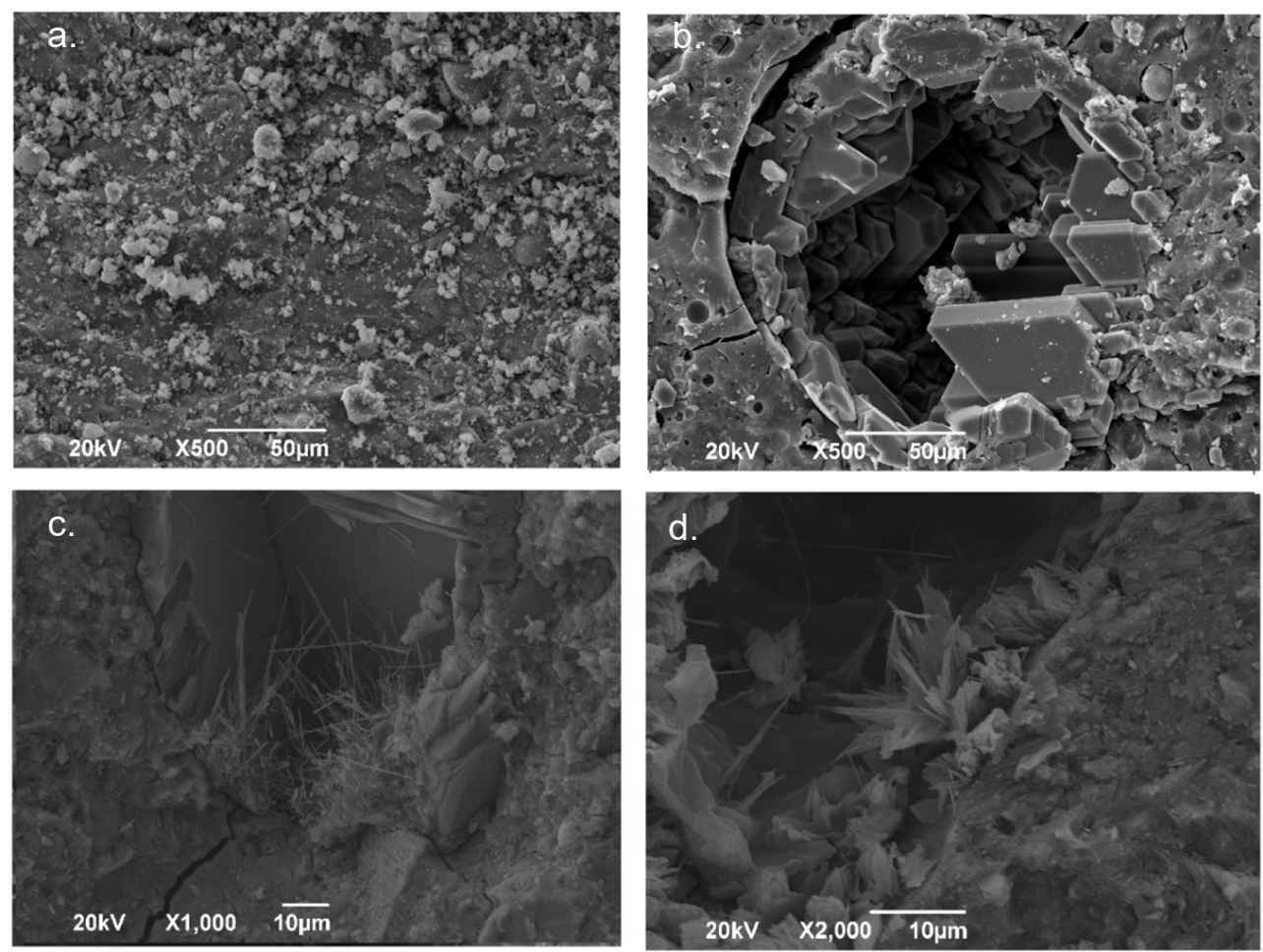

Figure 5. SEM micrographs of the pastes exposed for 180 days: (a) FA/OPC $\mathrm{Na}_{2} \mathrm{SO}_{4}$; (b) FA/OPC $\mathrm{MgSO}_{4}$; (c) $\mathrm{OPC} \mathrm{Na} \mathrm{SO}_{4}$; and (d) $\mathrm{OPC} \mathrm{MgSO}_{4}$. 
In the FA/OPC sample exposed to $\mathrm{MgSO}_{4}$, gypsum crystals were observed embedded in the alkali-activated matrix, as shown in Figure 5a. At a high magnification $(10,000 \times)$, needle-type crystals were observed, due to the reduced proportion of ettringite. For the FA/OPC concretes immersed in the $\mathrm{Na}_{2} \mathrm{SO}_{4}$ solution, no new phases formed, and no specific changes were observed in the morphology, as shown in Figure 5b. Similar micrographs have been reported in other studies [16]. For the OPC pastes immersed in $\mathrm{MgSO}_{4}$ and $\mathrm{Na}_{2} \mathrm{SO}_{4}$, the SEM micrographs, as shown in Figure 5c,d, confirmed the presence of ettringite, which was observed in the X-ray diffraction analysis. These results agree with those presented by [33]. No evidence of gypsum was found in the OPC specimens exposed to $\mathrm{MgSO}_{4}$, though gypsum was indicated by the XRD analysis.

\subsection{Susceptibility to Carbonation}

\subsubsection{Carbonation Depth}

Figure 6a presents the samples that were cured for a period of 28 days and then exposed to $\mathrm{CO}_{2}$ $1 \%\left(\mathrm{HR}=65 \%, \mathrm{~T}=25^{\circ} \mathrm{C}\right)$ for a period of 90 days; a phenolphthalein indicator was applied to reveal the carbonated depth. In general, the OPC samples presented shallower carbonation depths. To more precisely observe the carbonated zones, measurements of these zones were taken in different directions, and an average carbonation depth was obtained at the ages of 7, 14, 28, 60, 90,120, 150, 180 and 270 days of exposure; the results are presented in Figure $6 \mathrm{~b}$. In general, the carbonation depth increased in all the samples evaluated as the age of exposure increased. This increment was more notable for the hybrid FA/OPC alkali-activated samples.
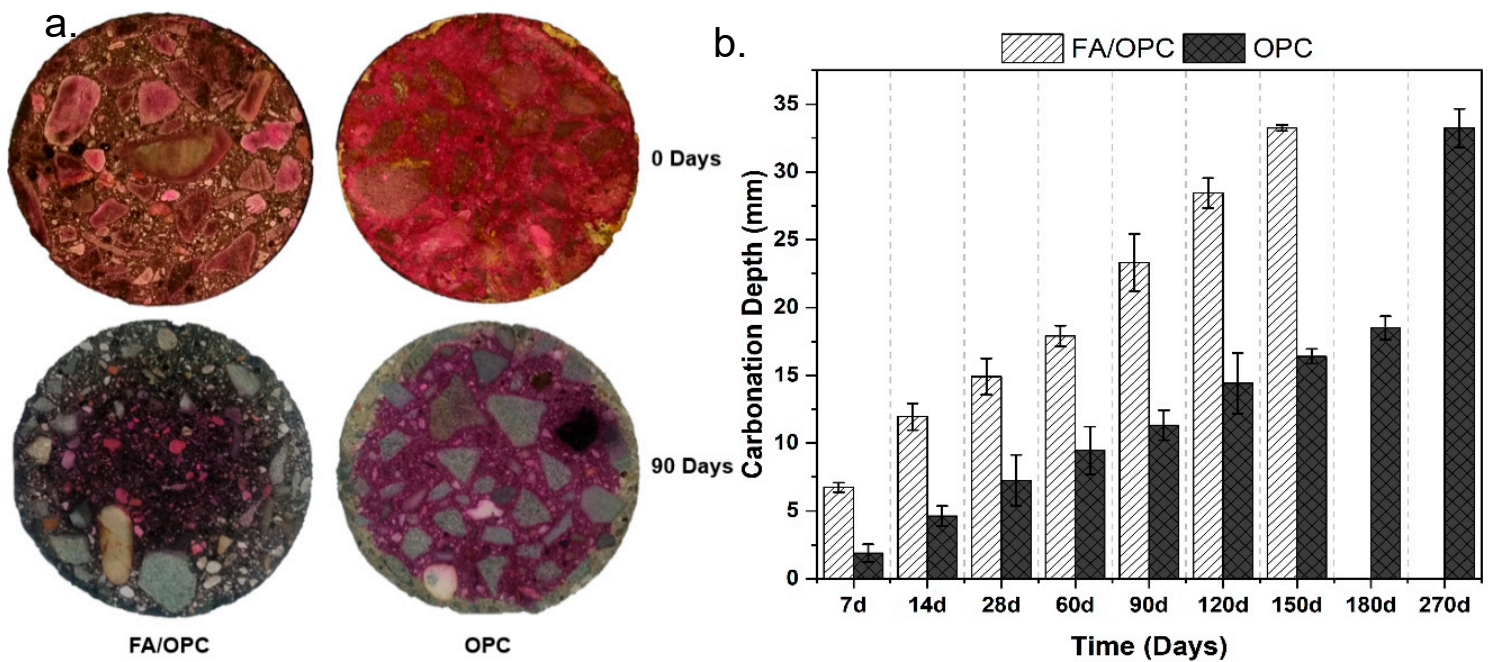

Figure 6. (a) Photographs of the concrete specimens at 90 days of exposure to $\mathrm{CO}_{2}$; and (b) Carbonation depth.

The carbonation coefficient was determined using the Equation (1), where $K_{c}$ is the carbonation coefficient, $X_{c}$ is the carbonation depth $(\mathrm{mm})$ and $\mathrm{t}$ is the time of exposure (days) [40]:

$$
K_{C}=\frac{X_{C}}{\sqrt{t}}
$$

Comparing the carbonation depth with the carbonation coefficient $\left(K_{c}\right)$ in Figure 7 , throughout the exposure period, the OPC concretes performed better than the FA/OPC samples. The carbonation coefficient of the FA/OPC concretes after 7 days of exposure was approximately $2.5 \mathrm{~mm} / \mathrm{day}^{1 / 2}$, while that of the OPC samples was $0.71 \mathrm{~mm} /$ day $^{1 / 2}$. At longer exposure times (150 days), the carbonation depth of the FA/OPC concretes (87\%) was greater than that of the OPC samples, with carbonation depths up to $43 \%$. This behavior coincides with that of the carbonation coefficient, where the FA/OPC 
samples presented a coefficient of $2.7 \mathrm{~mm} / \mathrm{day}^{1 / 2}$ at 150 days of exposure, while the OPC concretes presented values of $1.3 \mathrm{~mm} /$ day $^{1 / 2}$.

It is noted that the FA/OPC samples presented $100 \%$ carbonation at 180 days. The same behavior was observed by Behfarnia and Rostami [41], Bernal et al. [42], and Puertas et al. [20], for alkali-activated mortars and concretes based on blast furnace slag (GBFS) with respect to OPC concretes. These researchers attributed this behavior to certain chemical changes occurring in the matrix, such as the formation of calcium carbonate crystals, a decrease in the $\mathrm{pH}$ level of the pore solution, and the decomposition of the C-A-S-H gel formed. On the other hand, the OPC concretes or mortars have a higher $\mathrm{Ca}^{2+}$ content than the alkali-activated concretes or mortars; when the OPC matrix comes in contact with $\mathrm{CO}_{2}, \mathrm{CaCO}_{3}$ crystals form that precipitate in the pores, producing a barrier that prevents the diffusion of $\mathrm{CO}_{2}$. Therefore, carbonation reactions progress slower in OPC samples, and the carbonation of alkali-activated systems is higher [43-45]. In general, given that the matrix of alkali-activated concretes has low or no $\mathrm{Ca}(\mathrm{OH})_{2}$ content, the main carbonation reactant has to come from another source. Peter et al. [46], claimed that other constituents in the concrete can participate in the carbonation process, in particular the C-A-S-H/C-S-H gels.

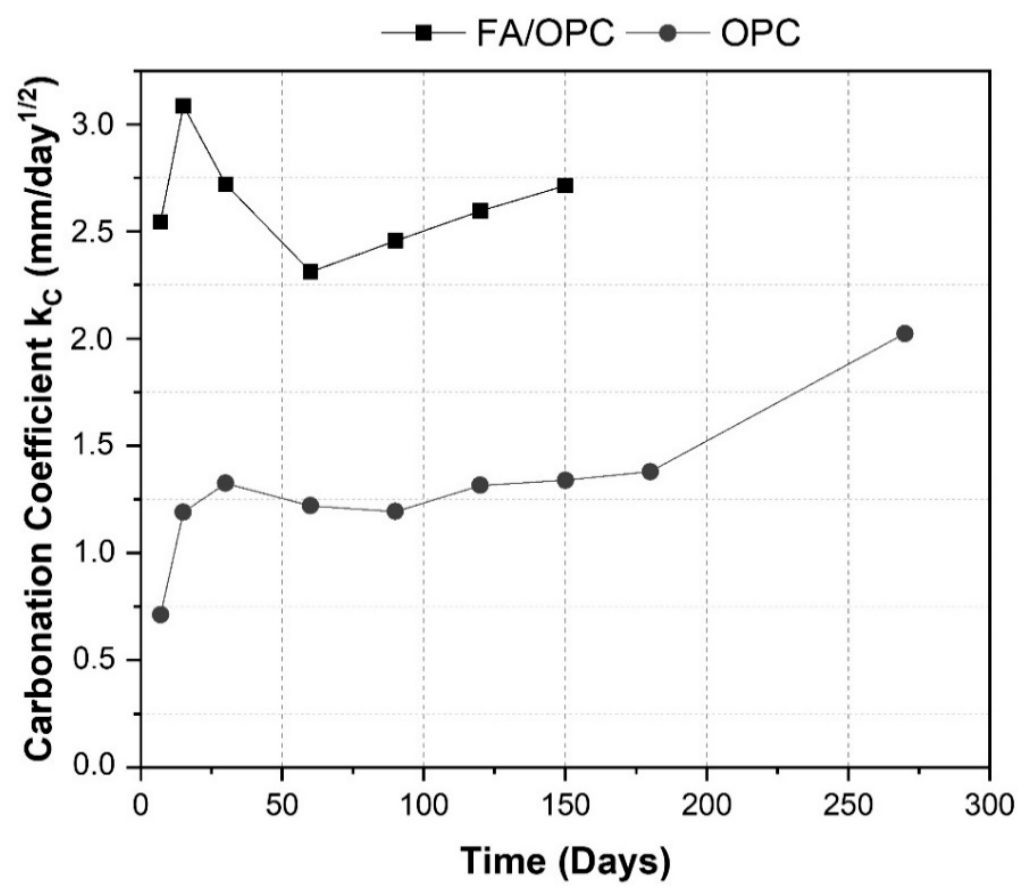

Figure 7. Concrete carbonation coefficient.

\subsubsection{Compressive Strength}

Figure 8 presents the compressive strength results of the alkali-activated concretes and those made with Portland cement, cured for a period of 28 days and then exposed to carbonation $\left(\mathrm{CO}_{2}\right)$ for 28,90 , 180 and 360 days of exposure. The noncarbonated FA/OPC and OPC concretes exhibited compressive strengths of $24.8 \mathrm{MPa}$ and $37.4 \mathrm{MPa}$, respectively. During the first 28 days of exposure, the compressive strength of the hybrid alkali-activated concretes decreased by $22 \%$ with respect to the noncarbonated concretes, whereas the OPC concretes increased in strength by $20 \%$. Similar tendencies were shown by the specimens exposed for longer periods of time (90 days); for the FA/OPC samples, the loss in strength significantly increased with time. At 180 days of exposure, the FA/OPC concretes had lost the most strength, with a residual strength of $21 \mathrm{MPa}$. Even though the alkali-activated concretes were completely carbonated, the residual strength is considered appropriate in terms of mechanical behavior for construction material in several civil engineering applications. In addition, a correlation was observed between the carbonation depth and the residual strength that was approximately 
linear for the concretes; the alkali-activated concretes presented the deepest carbonation depths, as well as the greatest losses in strength. Between 180 and 360 days of exposure, the compressive strengths of the FA/OPC concretes increased, reaching $23 \mathrm{MPa}$, while a significant loss was observed in the compressive strength of the OPC concretes compared with the samples exposed for 180 days. These results coincide with those reported by Puertas et al. [20], who determined that alkali-activated mortars based on GBFS do not decrease in compressive strength after 4 months of exposure to $\mathrm{CO}_{2}$, and that the OPC mortars do not gain strength after this period.

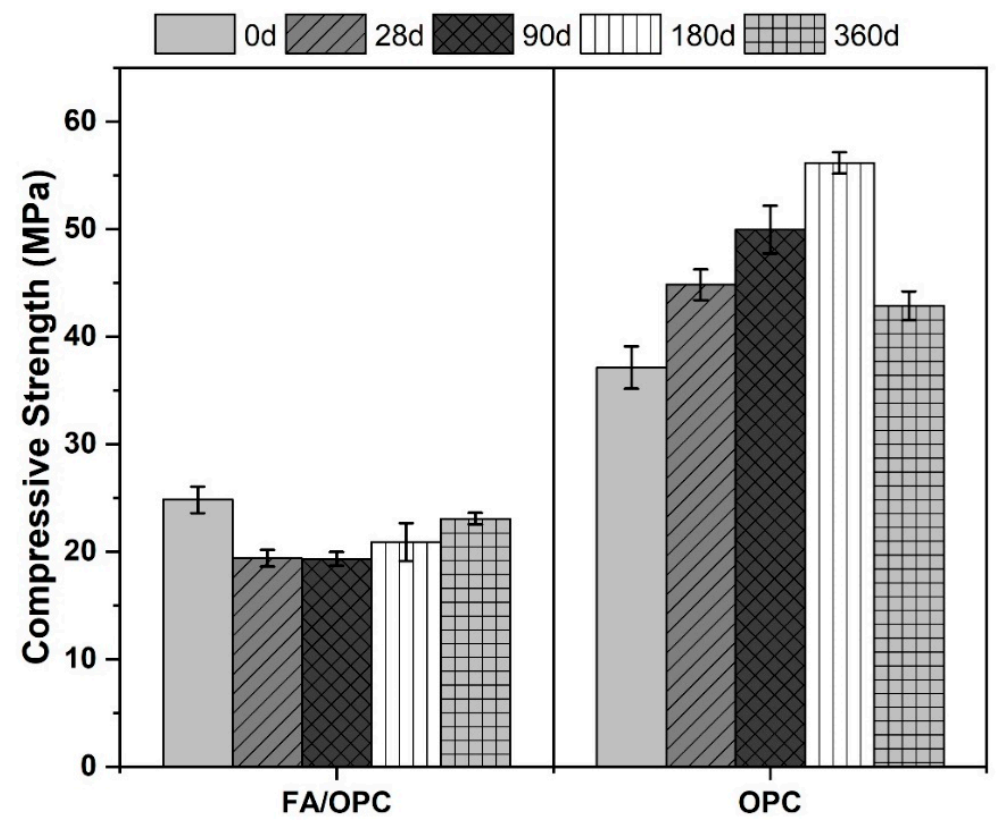

Figure 8. Compressive strength of the concrete at 28, 90, 180 and 360 days of exposure to carbonation.

\subsection{Exposure to Chlorides}

\subsubsection{Chloride Permeability}

Figure 9 presents the total transferred loads expressed in Coulombs for the concretes under study. In general, a decrease in the chloride permeability was observed with increasing time for all the mixtures.

The OPC concretes had a lower resistance to chloride ion permeability than the hybrid alkali-activated concretes. At the age of 28 days, all the samples were in the moderate permeability range, according to the values specified in the ASTM C1202 standard, by exhibiting the transferred loads of $2315 \mathrm{C}$ and $3256 \mathrm{C}$ for the FA/OPC and OPC concretes, respectively. However, at the curing age of 360 days, the FA/OPC concretes were in the low permeability range, and the OPC concrete remained in the moderate permeability range. In the FA/OPC concretes, reductions in the permeability of $29 \%$ and $40 \%$ were observed with respect to the standard sample (OPC) for the curing ages of 28 and 360 days, respectively.

In the interpretation of the data obtained by the chloride permeability test (ASTM C1202 standard), we must consider that this test is mainly a measure of the electrical conductivity of the concrete. The ion transport depends to a great extent on the structure of the pore network in the cementing matrix, whereas the electrical conductivity in the concrete is affected by both the structure of the pore network and the chemical composition of the pore solutions [47-49]. In the alkali-activated concretes, the pore solutions contain high concentrations of ionic species, mainly $\mathrm{Na}^{+}$and $\mathrm{OH}^{-}$[50-52]. The chloride permeability technique indicates the motion of all the ions in the structure, not just the chloride ions. For this reason, the results of the ASTM C1202 tests for alkali-activated concretes could be affected. Any $\mathrm{Na}^{+}$ions present in the pores of the material are expected to diffuse in the direction opposite to that 
in which the $\mathrm{Cl}^{-}$ions are electrically driven through the pore network, which can lead to a greater load transfer during the test. Therefore, a higher ionic force in the pore solution of the samples is expected to lead to higher values of transferred load, which means that the values observed in the alkali-activated concretes could be higher than the actual chloride permeability.

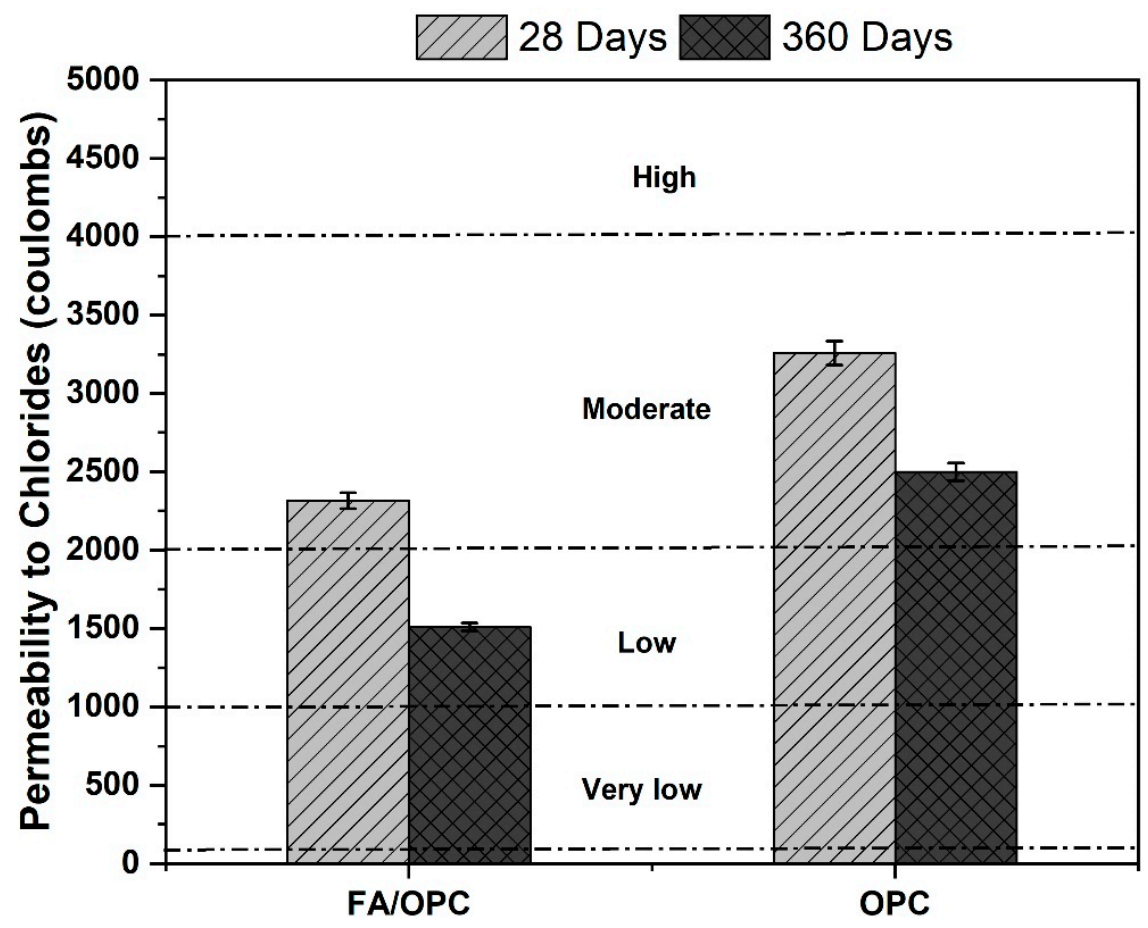

Figure 9. Rapid chloride permeability of the FA/OPC and OPC concrete at 28 and 360 days of curing.

Table 1 shows the instantaneous resistivity values exhibited by the different concretes analyzed and calculated based on the initial current measured in the chloride permeability test (ASTM C1202). The resistivity increased with curing time, which agrees with the chloride permeability results. Furthermore, the FA/OPC samples presented the best permeability behavior, reaching resistivity values that were $100 \%$ and $50 \%$ higher than those exhibited by the OPC concretes at ages of 28 and 360 curing days, respectively.

Table 1. Resistivity of the FA/OPC and OPC concretes at 28 and 360 days of curing.

\begin{tabular}{ccc}
\hline \multirow{2}{*}{ Curing Age (Days) } & \multicolumn{2}{c}{ Resistivity $(\boldsymbol{\Omega} \cdot \mathbf{m})$} \\
\cline { 2 - 3 } & FA/OPC & OPC \\
\hline 28 & 168.30 & 84.45 \\
360 & 198.22 & 133.65 \\
\hline
\end{tabular}

\subsubsection{Analysis of XRD and SEM after Chloride Exposition}

Figure 10 presents the X-ray spectra of the FA/OPC and OPC pastes after exposure to $\mathrm{NaCl}$ at $3.5 \%$ for a period of 180 days. For the OPC samples, hydration products were observed, $\mathrm{CH}$ : portlandite, and E: ettringite, as well as the crystalline phases present in the original material, Q: quartz, C: calcite, and H: hydrocalcite. The presence of a new crystalline phase, SF: Friedel's salt, was observed, which indicates that a chemical bond is the interaction mechanism between the cement and chloride. In the FA/OPC spectrum, crystalline phases corresponding to the raw materials were observed, such as C: calcite, Q: quartz, M: mullite, and H: hematite; the reaction between the chloride and the hybrid FA/OPC alkali-activated system did not change the mineralogical phases observed in Figure 4 (control samples). 


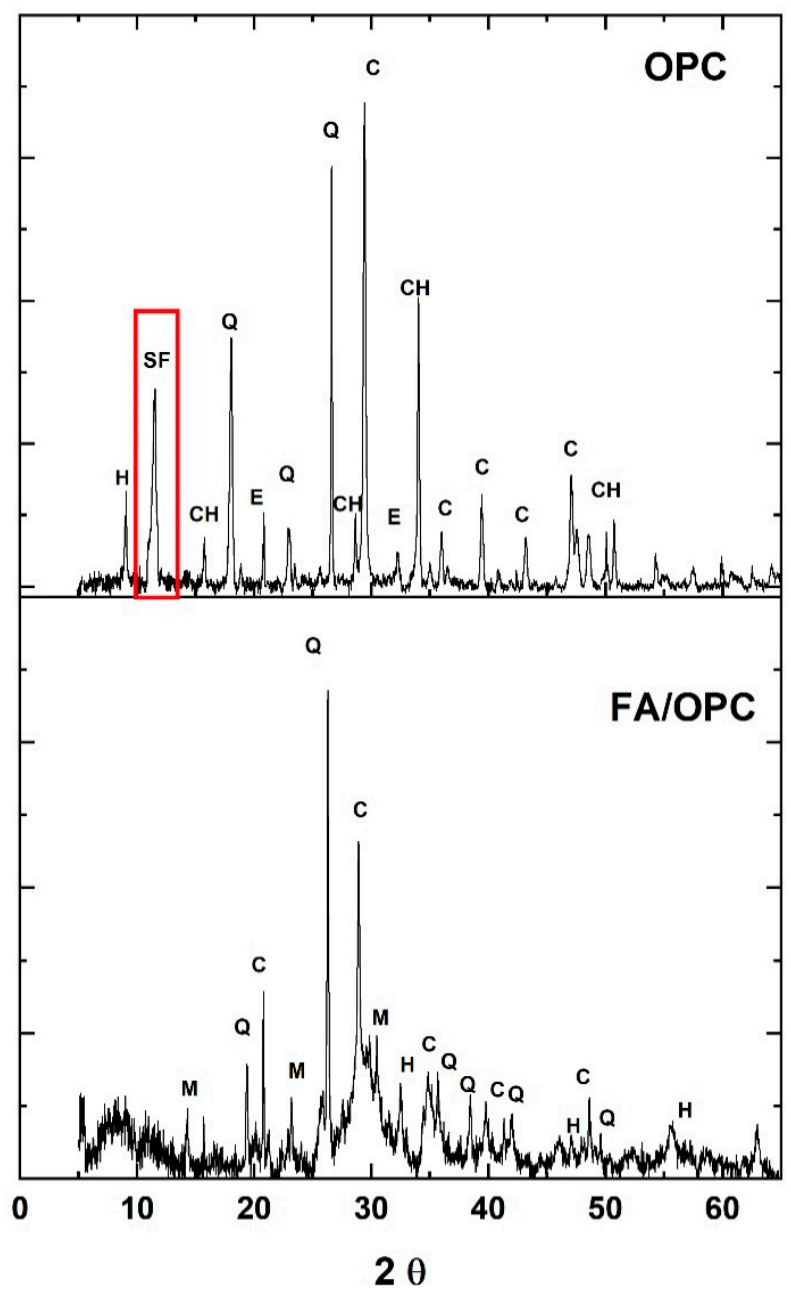

Figure 10. X-ray diffractogram of the FA/OPC and OPC pastes exposed to $3.5 \% \mathrm{NaCl}$ for a period of 180 days.

Figure 11 presents the SEM micrographs of the FA/OPC and OPC pastes exposed for 180 days to $\mathrm{NaCl}$ solutions at $3.5 \%$. In the FA/OPC sample, $\mathrm{NaCl}$ crystals (halite) were observed embedded in the matrix pores, as shown in Figure 11a. The EDS analysis corroborated the presence of $\mathrm{NaCl}$, as observed in the data reported in Table 2 for points 1 and 2. In the samples corresponding to the OPC pastes, the SEM micrographs and the EDS analyses of points 3 and 4 confirmed the presence of Friedel's salt, as observed in the X-ray diffraction analysis, as shown in Figure 11b.
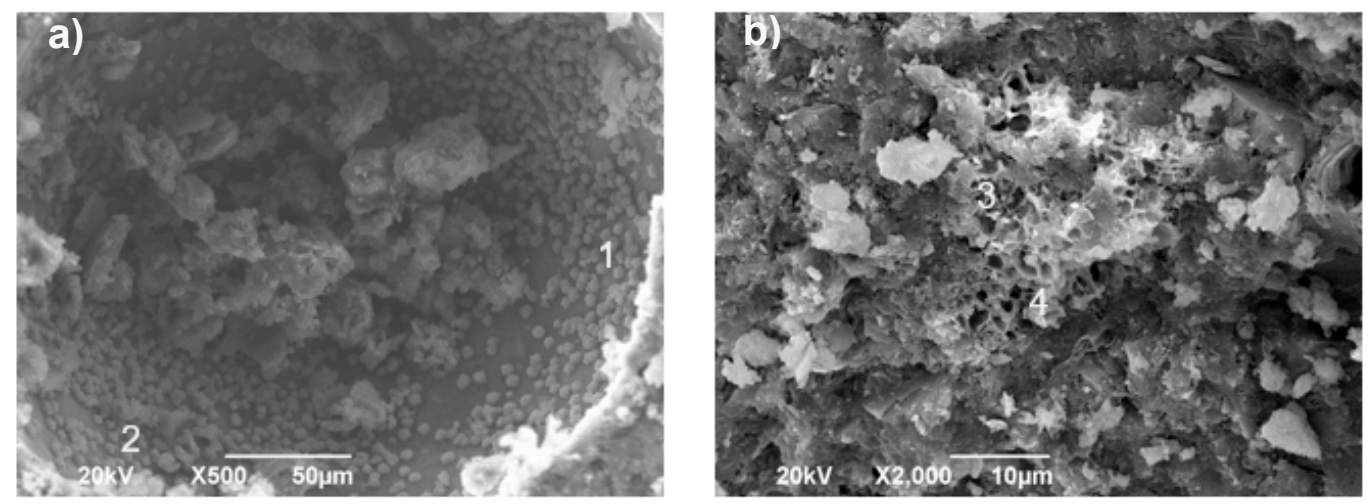

Figure 11. SEM micrographs of the pastes exposed to $\mathrm{NaCl}$ for a period of 180 days: (a) FA/OPC; and (b) OPC. 
Table 2. EDS spectrum of the samples exposed to $\mathrm{NaCl}$ at 3.5.

\begin{tabular}{ccccccccccc}
\hline Points & $\mathbf{C}$ & $\mathbf{O}$ & $\mathbf{A l}$ & $\mathbf{N a}$ & $\mathbf{S i}$ & $\mathbf{M g}$ & $\mathbf{F e}$ & $\mathbf{C a}$ & $\mathbf{C l}$ & Total \\
\hline 1 & - & 60.89 & 6.88 & 7.06 & 18.74 & - & 2.54 & 2.90 & 0.99 & 100 \\
2 & - & 58.80 & 7.29 & 9.36 & 20.53 & - & - & 2.11 & 1.90 & 100 \\
3 & 15.95 & 48.53 & 4.20 & - & 3.83 & 2.00 & 2.79 & 19.44 & 3.25 & 100 \\
4 & - & 52.62 & 3.51 & - & 4.20 & 5.19 & 6.58 & 21.38 & 2.50 & 100 \\
\hline
\end{tabular}

\section{Comparisons of the Results Obtained}

Table 3 presents the results obtained in the different tests: the exposure to sulphates, $\mathrm{CO}_{2}$ susceptibility and chloride permeability. The concrete performance was classified as excellent, good or bad according to the value obtained in each test.

Table 3. Concretes performance.

\begin{tabular}{cccc}
\hline & Concretes & FA/OPC & OPC \\
\hline \multicolumn{2}{c}{ Compressive strength (MPa)-28 d } & 24.80 & 37.40 \\
\hline & Performance test & \\
& Expansion (\%) $\mathrm{Na}_{2} \mathrm{SO}_{4}-1100 \mathrm{~d}$ & $0.140(++)$ & $2.394(-)$ \\
Exposure to sulphates & Compressive strength $\mathrm{Na}_{2} \mathrm{SO}_{4}-1100 \mathrm{~d}$ & $49.42(++)$ & $24.19(-)$ \\
& Expansion (\%) $\mathrm{MgSO}_{4}-1100 \mathrm{~d}$ & $1.221(-)$ & $0.765(-)$ \\
& Compressive strength $\mathrm{MgSO}_{4}-1100 \mathrm{~d}$ & $21.79(+)$ & $22.71(+)$ \\
\hline \multirow{2}{*}{ Exposure to $\mathrm{CO}_{2}$} & Carbonation front $(\mathrm{mm})-150 \mathrm{~d}$ & $33.24(-)$ & $16.4(+)$ \\
& Compressive strength-360 d & $23.09(+)$ & $42.89(++)$ \\
\hline Exposure to chlorides & Chloride permeability (coulombs)-360 d & $1509(+)$ & $2499(-)$ \\
\hline
\end{tabular}

(++) Excellent Performance; (+) Good Performance; (-) Bad performance.

In general, greater deterioration was observed in the specimens exposed to magnesium sulphate, with expansion percentages of 1.221 and $0.765 \%$ for the FA/OPC and OPC concretes, respectively. In contrast, in the presence of sodium sulphate, the expansion percentages were $0.140 \%$ and $2.394 \%$, respectively, at 1100 days of exposure, and no loss in strength was observed in the FA/OPC, compared with the $56 \%$ loss in strength for the OPC concretes, which was calculated comparing the results with those obtained with the control samples at the same curing age (1100 d, without sulphates). The method used to assess the sulphate attack corresponded to that specified for the mortars in ASTM standard C1012, both for pure and blended Portland cements. This test technique can be considered to be of accelerated character, given that this technique involves exposing specimens by immersion to a solution of $\mathrm{Na}_{2} \mathrm{SO}_{4}$ or $\mathrm{MgSO}_{4}$ at a concentration of $50 \mathrm{~g} / \mathrm{L}$, which is equivalent to 32,900 and $39,877 \mathrm{ppm}$ sulphate $\left(\mathrm{SO}_{4}{ }^{2-}\right)$, respectively, values that correspond to very severe exposure (higher than 10,000 ppm) according to building codes. The permeability of chlorides of FA/OPC concrete was $41 \%$ of the corresponding to OPC concrete. On the contrary, the hybrid concrete was more susceptible to carbonation than the control sample based on OPC.

\section{Materials and Methods}

\subsection{Materials}

A Colombian fly ash (FA) from a boiler located in a paper mill was used. The chemical composition of these materials presented in Table 4 was determined by X-ray fluorescence (XRF), using a Phillips MagiX-Pro PW-2440 spectrometer equipped with a rhodium tube and a maximum power of $4 \mathrm{KW}$. It was appreciated that approximately $56.5 \%$ of FA is composed of silica, aluminum and iron oxides in addition to a low calcium oxide content $(6.68 \%)$. The amount of unburnt material was remarkably high $($ Loss on ignition $=20.67 \%)$ and exceeded the standard specification defined in ASTM C618 
(6\% maximum). It was also relatively high in sodium oxides (7.94\%). The crystalline phases identified by $X$-ray diffraction in the FA were quartz $(\mathrm{Q})$, mullite $(\mathrm{M})$, hematite $(\mathrm{H})$, anhydrite $(\mathrm{A})$, and analcime (An); the apparent density was $2350 \mathrm{~kg} / \mathrm{m}^{3}$. The particle size analysis was carried out using laser granulometry, obtaining an average size of $22.1 \mu \mathrm{m}$ and its specific surface area, determined by Brunauer-Emmett-Teller method (BET), was $19.11 \mathrm{~m}^{2} / \mathrm{g}$. The Portland cement used in the mixtures was type UG (general use); the high LOI content present in OPC was due to the addition of limestone in the production process (estimated percentage $20 \%$ ). The crystalline phases identified in the OPC were tricalcium silicate $\left(C_{3} S\right)$, dicalcium silicate $\left(C_{2} S\right)$, tricalcium aluminate $\left(C_{3} A\right)$, gypsum $(Y)$ and calcite (C). The apparent density was $3.1 \mathrm{~g} / \mathrm{cm}^{3}$, and the average particle size was $21.5 \mu \mathrm{m}$.

Table 4. Chemical composition of the materials used: fly ash (FA) and ordinary Portland cement (OPC).

\begin{tabular}{|c|c|c|c|c|c|c|c|c|c|}
\hline Material & $\mathrm{SiO}_{2}$ & $\mathrm{Al}_{2} \mathrm{O}_{3}$ & $\mathrm{Fe}_{2} \mathrm{O}_{3}$ & $\mathrm{CaO}$ & MgO & $\mathrm{Na}_{2} \mathrm{O}$ & $\mathrm{SO}_{3}$ & $\mathrm{TiO}_{2}$ & LOI * \\
\hline FA & 28.53 & 19.18 & 8.80 & 6.68 & 2.24 & 7.94 & 2.71 & 1.62 & 20.67 \\
\hline $\mathrm{OPC}$ & 19.13 & 4.42 & 4.32 & 57.70 & 1.60 & - & 2.32 & - & 9.78 \\
\hline
\end{tabular}

A mixture of commercial sodium silicate $\left(\mathrm{Na}_{2} \mathrm{SiO}_{3} \cdot \mathrm{nH}_{2} \mathrm{O}\right)$ and industrial sodium hydroxide with $96.7 \%$ purity $(\mathrm{NaOH})$ was used as an alkaline activator. The composition of sodium silicate (SS) was $\mathrm{SiO}_{2}: 32.24 \%, \mathrm{Na}_{2} \mathrm{O}: 11.18 \%$ and $\mathrm{H}_{2} \mathrm{O}: 55.85 \%$.

\subsection{Preparation of Specimens and Test Carried Out}

The alkali-activated pastes and concretes were made with FA/OPC in a proportion of $80 \%$ and $20 \%$, respectively (Table 5). Previously, the synthesis of the binder was realized, and a response surface modelling methodology was used. The factors studied were the $\mathrm{SiO}_{2} / \mathrm{Al}_{2} \mathrm{O}_{3}$ and $\mathrm{Na}_{2} \mathrm{O} / \mathrm{SiO}_{2}$ molar ratios; the ranges selected were $3.0-4.8$ and $0.20-0.45$, respectively. The compressive strength was used as the response variable. The information obtained was processed using the software Minitab 17. The optimization of the compressive strength was obtained with the relations $\mathrm{Si} / \mathrm{Al}=4.50$ and $\mathrm{Na} / \mathrm{Si}=0.40$. Then, the dosage of the activator in the concrete mixture was adjusted to obtain these molar proportions, taking into account the chemical composition of the precursor and activator. The solution modulus $\left(\mathrm{SiO}_{2} / \mathrm{Na}_{2} \mathrm{O}\right)$ of the activator, which includes the proportion of $\mathrm{NaOH}$ and sodium silicate, was 1.10. For the production of the concrete, a coarse aggregate of type siliceous (maximum size: $19 \mathrm{~mm}$, apparent density: $2440 \mathrm{~kg} / \mathrm{m}^{3}$, and absorption: $2.55 \%$ ) and a river sand as the fine aggregate (finer module: 3.1 , apparent density: $2510 \mathrm{~kg} / \mathrm{m}^{3}$, and absorption: $1.72 \%$ ) were used. The proportion of coarse and fine aggregates was $42 \%$ and $58 \%$, respectively (see Table 5). The concretes were prepared with a liquid/solid ratio $(\mathrm{L} / \mathrm{S})$ of 0.48 . It should be clarified that $\mathrm{L}$ represents the water content present in the mixture in addition to that provided by the activator, and $S$ includes the solid phase represented by the precursor (FA), cement (OPC) and activator anhydrous. An OPC-based concrete was used as a reference material, as shown in Table 5. FA/OPC samples were cured at room temperature with a relative humidity greater than $90 \%$.

Table 5. Proportions of the components and liquid/solid ratio (L/S).

\begin{tabular}{cccccccc}
\hline \multirow{2}{*}{ Mixes } & \multicolumn{9}{c}{$\mathbf{K g} / \mathbf{m}^{3}$ Concrete } & \multirow{2}{*}{ L/S Ratio } \\
\cline { 2 - 7 } & OPC & FA & NaOH & Sodium Silicate & Sand & Gravel & \\
\hline Reference (OPC) & 400 & - & - & - & 972.7 & 704.4 & 0.48 \\
FA/OPC & 80 & 320 & 48.37 & 219.66 & 972.7 & 704.4 & 0.48 \\
\hline
\end{tabular}

The chemical resistance to sulphate attack was performed on the basis of ASTM C1012/C1012M-18b, exposing the samples to sodium sulphate $\left(\mathrm{Na}_{2} \mathrm{SO}_{4}\right)$ and magnesium sulphate $\left(\mathrm{MgSO}_{4}\right)$ solutions $(5 \%)$ at a temperature of $25^{\circ} \mathrm{C}$ for up to a period of 1100 days; the $\mathrm{pH}$ range of the solutions before use was 
from 6.0 to 8.0. According to the methodology specified in ASTM C1012, the solution was discarded after the reading of the bars and the mechanical test of the cubes in the standard intervals. Prismatic specimens $(50.8 \times 50.8 \times 285 \mathrm{~mm})$ were used to evaluate the longitudinal expansion and concrete cubes $(50.8 \times 50.8 \times 50.8 \mathrm{~mm})$ to determine the loss of compressive strength (ASTM C109). This loss was calculated by comparing the resistance obtained by the material immersed in the sulphate solution with that obtained at normal curing conditions and at the same curing age. Additionally, a visual inspection of the samples was carried out.

It is known that the carbonation process is a long-term reaction, therefore, an accelerated carbonation system was used to carbonate the concretes $\left(\mathrm{HR}=65 \%, \mathrm{~T}=25{ }^{\circ} \mathrm{C}\right.$ and $\left.\mathrm{CO}_{2}=1 \%\right)$; for this purpose, a specially designed chamber (Binder KBF 240 UL, $10-70{ }^{\circ} \mathrm{C}, 10-80 \%$ H.R., $1-10 \% \mathrm{CO}_{2}$ ) was used as shown in Figure 12. To evaluate the front of carbonation after exposure to $\mathrm{CO}_{2} \mathrm{concrete}$, cylinders of $76.2 \mathrm{~mm}$ in diameter by $152.4 \mathrm{~mm}$ in height were prepared. In order to maintain the radial direction at the ingress of $\mathrm{CO}_{2}$, the top and bottom of each of the cylinders was coated with an acrylic resin. Additionally, the loss of compressive strength was evaluated.

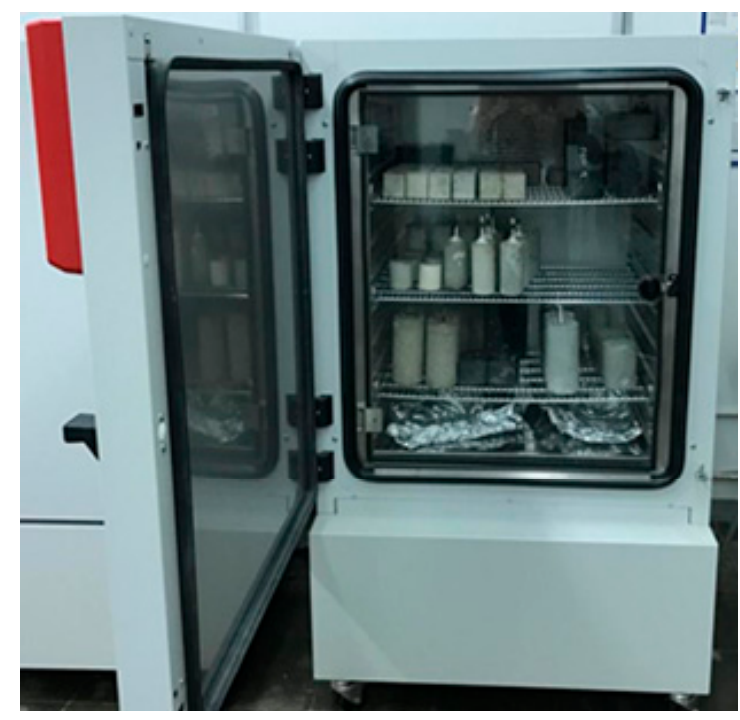

Figure 12. Climate chamber for the $\mathrm{CO}_{2}$ exposure under the controlled conditions.

The rapid chloride permeability test based on ASTM C1202 was employed to evaluate the performance in chlorides. The initial resistivity of the concretes was determined using the intensity of current at the beginning of the test. In general, the reported values of the tests correspond to the average of three specimens and the trial was conducted at curing ages of 28 and 360 days.

The microstructural analysis was performed on the alkali-activated (FA/OPC) and control pastes (OPC) exposed to the same aggressive conditions-sulfates and chlorides-using X-ray diffraction (XRD) and scanning electron microscopy (SEM) techniques. These tests were realized after 180 days of exposition. The XRD tests were conducted on a PanAnalytical X-ray diffractometer with Cu-radiation in a range of 5-60 degree. The SEM was realized using a JSM 6490LV JOEL with an acceleration voltage of $20 \mathrm{KV}$, the samples were evaluated in low vacuum mode and an Oxford Instruments Link-Isis X-ray spectrometer was used. The sample for the SEM testing was taken from the center of the fractured sample and the XRD analysis was performed using the rest of the sample. Traducción al Inglés. The XRD samples were previously dried at $50{ }^{\circ} \mathrm{C}$ for $24 \mathrm{~h}$ and then ground before the test.

\section{Conclusions}

The results obtained in this study confirm that the hybrid alkali-activated concretes (FA/OPC 80/20) evaluated are, in general, less susceptible to sulphate attack than traditional Portland cement concrete at ages of up to 1100 days of exposure. Based on the results, these concretes can be classified as 
having high resistance to sulphates, specifically to sodium sulphate. In addition, the FA/OPC concretes reported a lesser chloride ion permeability compared with the OPC concretes.

Conversely, the FA/OPC samples were more susceptible to carbonation. However, even though the carbonation coefficients were higher and higher strength losses were observed with respect to the OPC concretes, the residual strength of these samples after 360 days of exposure was $23 \mathrm{MPa}$ with a tendency to stabilize.

The mechanical and durability properties of the hybrid alkali-activated concrete (FA/OPC 80/20), even based on low-quality fly ash, make its use in the civil construction sector more feasible, especially in the prefabrication of blocks and other structural and non-structural elements.

Author Contributions: Conceptualization, methodology, resources, project administration, supervision and funding acquisition, R.M.d.G.; methodology, formal analysis, investigation, data curation, W.G.V.-S.; writing-original draft preparation, W.G.V.-S.; writing-review and editing, R.M.d.G. All authors have read and agreed to the published version of the manuscript

Funding: This research was funded by Colombian Institute for the Development of Science, Technology, and Innovation COLCIENCIAS (project, "Construction of prototype at the scale of rural housing using innovative materials with low carbon footprint," Contract 096-2016).

Acknowledgments: The authors, who are members of the Composite Materials Group (GMC) from the Centre of Excellence in New Materials (CENM), would like to thank Universidad del Valle (Cali, Colombia), in which the experimental work was carried out.

Conflicts of Interest: The authors declare no conflict of interest.

\section{References}

1. Aguirre, A.M.; Mejía de Gutiérrez, R. Durability of reinforced concrete exposed to aggressive conditions. Mater. Constr. 2013, 63, 7-38. [CrossRef]

2. Komljenović, M.; Baščarević, Z.; Marjanović, N.; Nikolić, V. External sulfate attack on alkali-activated slag. Constr. Build. Mater. 2013, 49, 31-39. [CrossRef]

3. Baščarević, Z.; Komljenović, M.; Miladinović, Z.; Nikolić, V.; Marjanović, N.; Petrović, R. Impact of sodium sulfate solution on mechanical properties and structure of fly ash based geopolymers. Mater. Struct. 2015, 48, 683-697. [CrossRef]

4. Alexander, M.; Bertron, A.; De Belie, N. RILEM State of the Art Reports, RILEM TC 211. In Performance of Cement-Based Materials in Aggressive Aqueous Environments; Springer: Berlin, Germany, 2013; Volume 10.

5. Aye, T.; Oguchi, C.T. Resistance of plain and blended cement mortars exposed to severe sulfate attacks. Constr. Build. Mater. 2011, 25, 2988-2996. [CrossRef]

6. Lothenbach, B.; Le Saout, G.; Gallucci, E.; Scrivener, K. Influence of limestone on the hydration of Portland cements. Cem. Concr. Res. 2008, 38, 848-860. [CrossRef]

7. Gollop, R.S.; Taylor, H.F.W. Microstructural and microanalytical studies of sulfate attack. IV. Reactions of a slag cement paste with sodium and magnesium sulfate solutions. Cem. Concr. Res. 1996, 26, 1013-1028. [CrossRef]

8. Fernández-Jiménez, A.; Palomo, J.G.; Puertas, F. Alkali-activated slag mortars: Mechanical strength behavior. Cem. Concr. Res. 1999, 29, 1313-1321. [CrossRef]

9. Douglas, E.; Bilodeau, A.; Brandstetr, J.; Malhotra, V.M. Alkali activated ground granulated blast-furnace slag concrete: Preliminary investigation. Cem. Concr. Res. 1991, 21, 101-108. [CrossRef]

10. Puertas, F.; Fernández-Jiménez, A. Mineralogical and microstructural characterisation of alkali-activated fly ash/slag pastes. Cem. Concr. Compos. 2003, 25, 287-292. [CrossRef]

11. Brough, A.R.; Atkinson, A. Sodium silicate-based, alkali-activated slag mortars: Part I. Strength, hydration and microstructure. Cem. Concr. Res. 2002, 32, 865-879. [CrossRef]

12. Abora, K.; Beleña, I.; Bernal, S.A.; Dunster, A.; Nixon, P.A.; Provis, J.L.; Arezki, T.-H.; Frank, W. Durability and Testing-Chemical Matrix Degradation Processes. In Alkali Activated Materials; Provis, J.L., van Deventer, J.S.J., Eds.; Springer: Dordrecht, The Netherlands, 2014; pp. 177-221.

13. Singh, B.; Ishwarya, G.; Gupta, M.; Bhattacharyya, S.K. Geopolymer concrete: A review of some recent developments. Constr. Build. Mater. 2015, 85, 78-90. [CrossRef]

14. Škvára, F.; Jílek, T.; Kopeckỳ, L. Geopolymer materials based on fly ash. Ceram Silik 2005, 49, $195-204$. 
15. Puertas, F.; Mejía de Gutiérrez, R.; Fernández-Jiménez, A.; Delvasto, S.; Maldonado, J. Morteros de cementos alcalinos. Resistencia química al ataque por sulfatos y al agua de mar. Mater. Constr. 2002, 52, 55-71. [CrossRef]

16. Ismail, I.; Bernal, S.A.; Provis, J.L.; Hamdan, S.; van Deventer, J.S.J. Microstructural changes in alkali activated fly ash/slag geopolymers with sulfate exposure. Mater. Struct 2012, 46, 361-373. [CrossRef]

17. Bernal, S.A. Microstructural Changes Induced by $\mathrm{CO}_{2}$ Exposure in Alkali-Activated Slag/Metakaolin Pastes. Front. Mater. 2016, 3, 43. [CrossRef]

18. Deja, J. Carbonation aspects of alkali activated slag mortars and concretes. Silic. Ind. 2002, 67, 37-42.

19. Palacios, M.; Puertas, F. Effect of Carbonation on Alkali-Activated Slag Paste. J. Am. Ceram. Soc. 2006, 89, 3211-3221. [CrossRef]

20. Puertas, F.; Palacios, M.; Vázquez, T. Carbonation process of alkali-activated slag mortars. J. Mater. Sci. 2006, 41, 3071-3082. [CrossRef]

21. Bernal, S.A. 12-The resistance of alkali-activated cement-based binders to carbonation. In Handbook of Alkali-Activated Cements, Mortars and Concretes; Pacheco-Torgal, F., Labrincha, J.A., Leonelli, C., Palomo, A., Chindaprasirt, P., Eds.; Woodhead Publishing: Sawston, UK, 2015; pp. 319-332. [CrossRef]

22. Bernal, S.A.; Nicolas, R.S.; Provis, J.L.; Mejía de Gutiérrez, R.; van Deventer, J.S.J. Natural carbonation of aged alkali-activated slag concretes. Mater. Struct. 2014, 47, 693-707. [CrossRef]

23. Rajamane, N.P.; Nataraja, M.; Lakshmanan, N.; Dattatreya, J. Rapid chloride permeability test on geopolymer and Portland cement. Indian Concr. J. 2011, 85, 21-26.

24. Ganesan, N.; Abraham, R.; Deepa Raj, S. Durability characteristics of steel fibre reinforced geopolymer concrete. Constr. Build. Mater. 2015, 93, 471-476. [CrossRef]

25. Olivia, M.; Nikraz, H. Durability of Fly Ash Geopolymer Concrete in a Seawater Environment. In Proceedings of the CONCRETE 2011 Conference, Perth, Australia, 8-12 October 2011.

26. Shayan, A.; Xu, A.; Andrews-Phaedonos, F. Field performance of geopolymer concrete, used as a measure towards reducing carbon dioxide emission. In Proceedings of the 26th Concrete Institute of Australia Conference, Gold Coast, Australia, 16-18 October 2013.

27. Ma, Q.; Nanukuttan, S.V.; Basheer, P.A.M.; Bai, Y.; Yang, C. Chloride transport and the resulting corrosion of steel bars in alkali activated slag concretes. Mater. Struct. 2016, 49, 3663-3677. [CrossRef]

28. Tennakoon, C.; Shayan, A.; Sanjayan, J.G.; Xu, A. Chloride ingress and steel corrosion in geopolymer concrete based on long term tests. Mater. Des. 2017, 116, 287-299. [CrossRef]

29. Shi, C.; Fernández-Jiménez, A.; Palomo, A. New cements for the 21st century: The pursuit of an alternative to Portland cement. Cem. Concr. Res. 2011, 41, 750-763. [CrossRef]

30. Garcia-Lodeiro, I.; Donatello, S.; Fernández-Jiménez, A.; Palomo, A. Hydration of Hybrid Alkaline Cement Containing a Very Large Proportion of Fly Ash: A Descriptive Model. Materials 2016, 9, 605. [CrossRef] [PubMed]

31. Snelson, D.G.; Kinuthia, J.M. Resistance of mortar containing unprocessed pulverised fuel ash (PFA) to sulphate attack. Cem. Concr. Compos. 2010, 32, 523-531. [CrossRef]

32. Yang, S.; Zhongzi, X.; Mingshu, T. The process of sulfate attack on cement mortars. Adv. Cem. Based Mater. 1996, 4, 1-5. [CrossRef]

33. Sata, V.; Sathonsaowaphak, A.; Chindaprasirt, P. Resistance of lignite bottom ash geopolymer mortar to sulfate and sulfuric acid attack. Cem. Concr. Compos. 2012, 34, 700-708. [CrossRef]

34. Bakharev, T. Durability of geopolymer materials in sodium and magnesium sulfate solutions. Cem. Concr. Res. 2005, 35, 1233-1246. [CrossRef]

35. Ismail, I.; Bernal, S.A.; Provis, J.L.; San Nicolas, R.; Brice, D.G.; Kilcullen, A.R.; Hamdanb, S.; van Deventerad, J.S.J. Influence of fly ash on the water and chloride permeability of alkali-activated slag mortars and concretes. Constr. Build. Mater. 2013, 48, 1187-1201. [CrossRef]

36. Mehta, P.K.; Monteiro, P.J.M. Concrete Microestructure, Properties, and Material, 3rd ed.; McGraw Hill Companies: New York, NY, USA, 2006.

37. Lee, N.K.; Lee, H.K. Reactivity and reaction products of alkali-activated, fly ash/slag paste. Constr. Build. Mater. 2015, 81, 303-312. [CrossRef]

38. Ruiz, A.E.; Putnis, C.V.; Jiménez-López, C.; Rodriguez-Navarro, C. An atomic force microscopy study of calcite dissolution in saline solutions: The role of magnesium ions. Geochim. Cosmochim. Acta 2009, 73, 3201-3217. [CrossRef] 
39. Manzano, H.; González-Teresa, R.; Dolado, J.S.; Ayuela, A. X-ray spectra and theoretical elastic properties of crystalline calcium silicate hydrates: Comparison with cement hydrated gels. Mater. Constr. 2010, 60, 7-19. [CrossRef]

40. Ferreira. Relationship between results of accelerated and natural carbonation in various concretes. In International RILEM Conference on the Use of Recycled Materials in Building and Structures; Vázquez, E., Hendriks, C.F., Janssen, G.M.T., Eds.; RILEM Publications SARL: Paris, France, 2004; pp. 988-997.

41. Behfarnia, K.; Rostami, M. An assessment on parameters affecting the carbonation of alkali-activated slag concrete. J. Clean Prod. 2017, 157, 1-9. [CrossRef]

42. Bernal, S.A.; Rodríguez, E.; Mejía de Gutiérrez, R.; Rose, V.; Puertas, F.; Delvasto, S. Carbonation behavior of mortar produced by alkali-activation of a granulated blast furnace slag. In Proceedings of the 23rd International Conference of Solid Waste Technology and Management, Widener University, Philadelphia, PA, USA, 30 March-2 April 2008.

43. Adam, A. Strength and Durability Properties of Alkali Activated Slag and Fly Ash-Based Geopolymer Concrete. Ph.D. Thesis, RMTI University, Melbourne, Australia, 2009.

44. Al-Otaibi, S. Durability of concrete incorporating GGBS activated by water-glass. Constr. Build. Mater. 2008, 22, 2059-2067. [CrossRef]

45. Bilim, C.; Atiş, C.D. Carbonation resistance of slag mortars activated by different alkali activators. Turk. J. Eng. TUJE 2017, 1, 1-4. [CrossRef]

46. Peter, M.A.; Muntean, A.; Meier, S.A.; Böhm, M. Competition of several carbonation reactions in concrete: A parametric study. Cem. Concr. Res. 2008, 38, 1385-1393. [CrossRef]

47. Bernal, S.A.; Mejía de Gutiérrez, R.; Pedraza, A.L.; Provis, J.L.; Rodriguez, E.D.; Delvasto, S. Effect of binder content on the performance of alkali-activated slag concretes. Cem. Concr. Res. 2011, 41, 1-8. [CrossRef]

48. Chi, M. Effects of dosage of alkali-activated solution and curing conditions on the properties and durability of alkali-activated slag concrete. Constr. Build. Mater. 2012, 35, 240-245. [CrossRef]

49. Shi, C. Another Look at the Rapid Chloride Permeability Test (ASTM C1202 or ASSHTO T277); FHWA Resource Center, Federal Highway Administration: Baltimore, MD, USA, 2003. Available online: https://collaboration.fhwa.dot. gov/dot/fhwa/hpc/Lists/aReferences/Attachments/251/RAPCL202RHime.pdf (accessed on 1 April 2020).

50. Gruskovnjak, A.; Lothenbach, B.; Holzer, L.; Figi, R.; Winnefeld, F. Hydration of alkali-activated slag: Comparison with ordinary Portland cement. Adv. Cem. Res. 2006, 18, 119-128. [CrossRef]

51. Lloyd, R.R.; Provis, J.L.; van Deventer, J.S.J. Pore solution composition and alkali diffusion in inorganic polymer cement. Cem. Concr. Res. 2010, 40, 1386-1392. [CrossRef]

52. Song, S.; Jennings, H.M. Pore solution chemistry of alkali-activated ground granulated blast-furnace slag. Cem. Concr. Res. 1999, 29, 159-170. [CrossRef]

Sample Availability: Not Available.

(C) 2020 by the authors. Licensee MDPI, Basel, Switzerland. This article is an open access article distributed under the terms and conditions of the Creative Commons Attribution (CC BY) license (http://creativecommons.org/licenses/by/4.0/). 